\title{
Empowerment in the Context of Transformational Change: A Study of Acquisitions and Privatizations in Eastern Europe
}

\author{
Diether Gebert, Reiner Piske, Tünde Baga, Ralf Lanwehr, \& Eric Kearney \\ Technische Universitat Berlin
}

This paper examines conditions under which empowerment (decision autonomy, dialogic leadership) is connected with positive and negative effects, respectively, in regard to managing transformational change in Eastern Europe. Acquisitions by foreign investors in Poland and Russia ( $N=45$ companies) and privatizations through employee buy-out in Romania ( $N=5$ companies) are contrasted in this study. It is shown that empowerment within these two variants of transformational change is connected in different ways with success indicators of crisis management. From these findings, we deduce practical consequences for empowerment and transformational change, along with suggestions for future research. Keywords: empowerment, transformational change, change management, acquisitions, privatizations.

The essence of the empowerment movement that has gained popularity in the 1990s (Hardy/Leiba-O'Sullivan, 1998; Herrenkohl et al., 1999) can be summarized by the following thesis: Employees of an organization should not be treated as objects by a centralistic and directive form of leadership; instead, a decentralized and dialogic leadership should provide them with the opportunities for self-regulation and for being active subjects (Pearce \& Sims, 2002). In this paper, promoting the experience of being an active subject is the defining criterion of empowerment. Less other-directedness and more self-directedness thus lead to the two variants of expanding decision autonomy on the one hand and facilitating dialogic leadership (critical upward communication) on the other. These measures of granting decision autonomy and fostering dialogic leadership have in common that they both increase an individual's potential for exerting influence on the content of operational goals and the way in which these are attained. Each of these measures (granting decision autonomy and fostering dialogic leadership) creates opportunities for the employee to enhance his or her ability level (Leach et al., 2005) and to thus generate new potentials. Moreover, each measure enables the employee to act in accord with his or her beliefs and thus in line with his or her self-concept (Fiol et al., 1999).

This concept of empowerment has met with great acceptance in the scientific community and has proved successful in many Western countries (Wageman, 2001). It should not be taken for granted, however, that the same level of success will occur naturally in Eastern European contexts, since many of the local managers and employees were socialized in the spirit of a "closed society" (Gebert/Boerner, 1999). In this model of the closed society, autonomy, dialogue, or personal initiatives are not part of the role definitions that members of an organization develop for themselves. The cooperation model implied by the concept of empowerment thus contradicts the relatively stable belief systems and preferences of many members of the organization. Experience in the context of organizational development clearly shows, however, that the necessary changes of attitudes require long-term learning processes (Gebert, 2002). Empowerment in the sense of fostering the subject-status (as opposed to an object-status) may thus prove less successful in Eastern Europe, and may conceivably even turn out to be dysfunctional.

Therefore, the consequences of empowerment depend upon the respective context. By context, one should not merely think of processes of socialization, i.e. societal characteristics. The specific and unique 
conditions of companies must also be considered as a context variable that influences the outcomes of empowerment (Boerner/Gebert, 1997). In this regard, the type of transformational change pursued in an organization is crucial for mastering the economically critical situation following the political changes of 1989 in Eastern Europe (Staniszkis, 1991). This is the main point of the following analysis:

We examine two variants of transformational change in Eastern Europe: the acquisition of companies by foreign investors and the privatization of former state-owned organizations by employee buy-out, respectively. We will show that empowerment - in the sense of facilitating a subject-status - is connected in different ways with the management of intra-organizational change processes, depending upon whether empowerment occurs in the context of acquisitions or in the context of an employee buy-out.

We will show that empowerment is - at least in the initial stages - clearly conducive to managing change following a takeover by a foreign investor. In the context of privatization (here: employee buy-out with no additional investments of capital by third parties), however, empowerment initially engenders significant detrimental effects. We will explain in detail why this is so.

On the theoretical level, we thus interpret the type of transformational change as a moderator variable. Figure 1 illustrates the main points of our analysis.

In the acquisition study, we examine the relationship between empowerment and crisis management by operationalizing the facilitation of the subject-status via the enhancement of decision autonomy and successful change management via the (subsequent) quality of cooperation between the acquired company and the foreign investor. In the privatization study, we analyze the connection between empowerment and crisis management by operationalizing the fostering of the subject-status via the promotion of dialogic leadership and crisis management via the fostering of the innovativeness of the organization (see explanations below).

The results of our study show not only that the effects of empowerment depend upon the respective context. In the acquisition study, the relationship between empowerment and change management is not merely linear and positive, but reveals an inverted u-shaped, curvilinear function.

Analogously, in the privatization study, the relationship between empowerment and change management is not simply linear and negative, but likewise curvilinear, albeit in this case $u$-shaped. This means that the effects of empowerment also vary depending upon the level of empowerment in the respective setting. Regarding the acquisition study, for example, very high levels of empowerment are apparently counterproductive. Since the effects of empowerment are contingent upon context and the level of empowerment, general statements about the consequences of empowerment seem to be of little value.

\section{Comments Concerning Methods}

Both studies were partial projects within more long-term research projects studying transformational change in Eastern European companies. We had originally planned neither study with the objective of systematically comparing empowerment effects of acquisition processes with empowerment effects of privatization processes. If this had been the original intention, the independent variable of empowerment as well as the dependent variable of coping with transformational change should have been operationalized in the same way in both studies. This is not the case, however, as the two studies were conducted in partial independence of one another. This partial independence is reflected in the fact that the main question regarding the relationship between empowerment and managing transformational change is specified differently in the two studies, in order to adapt to the respective circumstances of each study.

In the privatization study, we measure the success of the transformational change by the innovativeness of the organization, since successful changes in the studied context depend primarily on innovations (Baga, 2004). In the acquisition study, we measure the (preliminary) success of transformational change by the quality of cooperation between the acquired company and the foreign investor, since acquisitions by foreign organizations often cause cooperation problems due to different cultures (Piske, 2003; Kelly et al., 2002). Analogously, we operationalize the construct empowerment via dialogic 
Journal of Leadership and Organizational Studies, 2006, Vol. 12, No. 3

Figure 1: Overview of the examined relationships

Moderator:
Empowerment Type of Transformational Change Criterion for Change Management

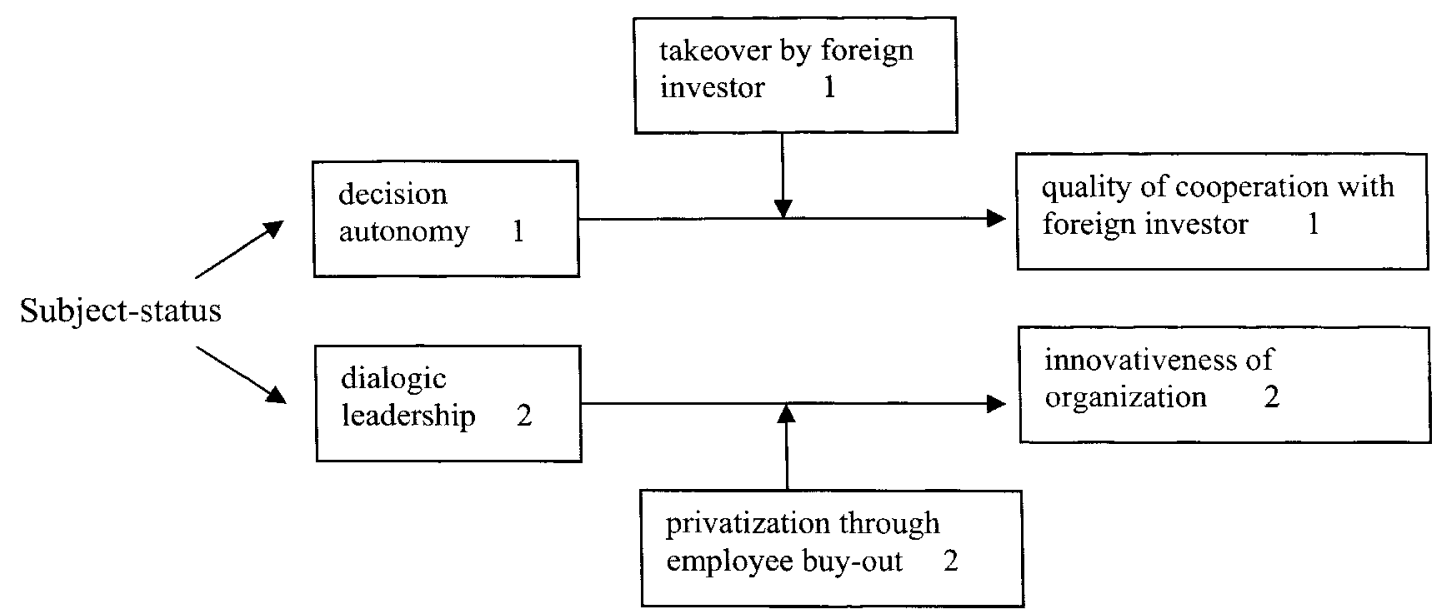

leadership in the privatization study and via decision autonomy in the acquisition study.

Initially, we had expected an inverted Ushaped relationship between empowerment and successful crisis management in both studies. Ex post, however, this hypothesis was only confirmed in the acquisition study, not in the privatization study. The differences regarding the empirical relationship between empowerment and indicators of crisis management have led us to ponder the explanation for these differences. Only after this analysis were we able to "discover" similarities and differences in the processes of the two variants of transformational change that we had not considered before. We then revised our explanations concerning the results of both studies. In the following, we will present this revised and most current interpretation.

The explanations provided below are predominantly of an ex post-nature and thus require further study. We have developed these explanations in some detail, in order to stimulate further research. Despite the different operationalizations of the respective dependent and independent variables, we believe that it is possible to discuss both studies within the same frame of reference: granting decision autonomy and fostering dialogic leadership are merely different operationalizations of the same basic construct "empowerment", which we have defined as the degree to which an individual's influence on the content of operational goals and the way in which these are attained is increased (see above). This constitutes the crucial link between the two studies. The same holds true with respect to the dependent variable: the quality of (trustful) cooperation and innovativeness are functionally equivalent success criteria concerning transformational change management. They are both prerequisites for future economic success. Thus, we not only deem it possible, but also sensible to discuss both studies in one paper.

\section{Theory}

Acquisitions and privatizations constitute a so-called transformational change (Tushman \& Romanelli, 1985). A transformational change occurs when the depth structure of an organization - the so-called archetype (Greenwood/Hinings, 1996) - is altered. Gersick (1991) defines this depth structure as a specific configuration of product, market, and technology units, the concomitant power and control distributions, as well as the basic beliefs and values.

Usually, such a transformational change is an answer to massive changes in the environment (Romanelli/Tushman, 1994). Indeed, this characterizes the circumstances regarding the acquisitions and privatizations in the late 1990s studied here. Following the political transitions in 1989 in Eastern Europe (Staniszkis, 1991), the change processes occur in a context marked by a profound societal and 
economic crisis (Baga, 2004). At that time, many of the companies participating in the study stood on the verge of financial ruin (Piske, 2003). This was evident, for instance, in the companies' massive reduction of their work force. Moreover, many companies could no longer pay their employees, many of whom thus experienced existential fears.

Concerning theory, it thus appears useful to study this transformational process against the backdrop of the stress and coping model proposed by Lazarus (1991). This model describes how persons attempt to cope with threatening situations. Within his action theory, Lazarus (1991) distinguishes between two cognitive appraisal processes. In the first appraisal (primary appraisal), the situation is evaluated with respect to its relevance and to the degree to which it constitutes a threat. In the subsequent secondary appraisal, a situation that has previously been categorized as threatening is evaluated regarding whether or not the person has action options at his or her disposal to cope with the threatening situation. In the secondary appraisal, the situation is thus appraised concerning the degree of situational control. The construct situational control is defined by the degree to which the person possesses action options for mastering the aversive situation. If a person perceives sufficient situational control, he or she will exhibit coping behaviour aimed at resolving the threatening situation.

Since previous attempts at managing the crisis in Eastern European companies had met with little success, the situation before the acquisition or privatization, respectively, was threatening for both employees and managers. From their perspective, the chance that they could overcome this crisis was remote. The situation was thus experienced as aversive and as requiring change. At the same time, due to the low situational control it was not perceived as changeable. According to Lazarus (1991), persons who find themselves in such circumstances tend either to run from the situation (i.e., leave the company) or to internally adapt to it (e.g., by lowering their standards). In some companies, qualified employees did indeed resign at the time of the study (Baga, 2004). The situation thus became even more threatening for the remaining work force.

With regard to crisis management, it is thus crucial to enhance situational control, so that the situation is not only perceived as requiring change, but also as changeable. The latter requires that the company obtains additional resources (e.g., in the form of capital) that were not present before and provide new action options. Moreover, perceiving the situation as changeable presupposes that the employees are able to evaluate the new action options. This entails a cognitive control of the situation, so that the most promising solutions can be selected from the spectrum of options. A precondition for this is that the workforce shares a clear and mutual goal orientation (Gebert et al. 2004).

In sum, an increase in material and cognitive situational control is called for. This marks the decisive theory-related difference between the two strategies of transformational change described above. We will show that the acquisition strategy tends to enable this twofold increase in situational control. This is not the case concerning the privatization strategy of employee buy-out, however. Overall, the finding emerges that the two examined strategies of transformational change provide markedly different contexts for empowerment. An increase in material and cognitive situational control is required in order for empowerment (e.g., in the form of delegating decision-making powers and thus promoting decision autonomy) to take effect. If, on the other hand, there is no increase in material and cognitive situational control over the crisis, empowerment (e.g., in the form of dialogic leadership) will initially tend to cause confusion and amplify the existing feelings of helplessness. These assertions are explained in more detail below.

\section{Study 1 (Acquisition)}

\section{Theory and Hypothesis}

We have emphasized the insufficient material and cognitive situational control over the economic crisis as the crucial unfavourable context condition. The takeover substantially changes this situation. If a foreign investor develops and communicates a new strategy and on this basis invests in new facilities and machines - which is the case in all of the industrial companies studied here - the employees have sufficient material and cognitive situational control to enable the company to assert itself on the market and to overcome the crisis. The process of acquisition implies a transformational change and thus constitutes a threat for some employees (e.g., 
via structural and process changes in the organization). At the same time, however, the new strategy comprising the new facilities and machines increases the situational control over the economic circumstances. Thus, hope is fostered (Piske, 2003), since the investments of the foreign organization furthermore indicate that the investor considers the acquired company to be capable of positive developments.

If the managers and employees have decision competencies regarding important aspects of implementing the (new) strategic orientation, they have the right to decide how the facilities and machines should be used and thus to define and test individual paths. The delegation of decision-making competencies makes sense because heightened material and cognitive situational control is the prerequisite for making any important decision. In this way, learning processes are set into motion that expand the spectrum of available crisis management strategies: New action options are discerned and the competencies for practically implementing these action options are facilitated. Over time, situational control increases under these circumstances.

Since crisis management is in the own interest of the members of the organization, an increase in situational control leads to more initiatives concerning the solution of the existing problems. Empowerment motivates, because the situation is not only experienced as requiring change but also as changeable (Gebert et al., 2002).

This provides the basis for an improved quality of cooperation between the foreign investor and the acquired company. According to our definition, the quality of cooperation is high when managers and employees of the acquired company regard the foreign investor as competent and serious, and when they work with the foreign investor in an open and trustworthy manner (Piske, 2003).

The foreign investor as well as the managers and employees of the acquired companies will interpret intermediate, small successes engendered by the change initiatives - which were enabled by the increase in situational control - as indications that the right path has been found and that the new strategic orientation introduced by the foreign investor and based on new facilities and machines is beginning to take effect. This fosters a mutual appreciation.
In this process, employees and managers not only learn action alternatives for coping with critical situations on a task level. They also learn on an interactive level. The combination of increasing situational control through new facilities and machines as well as through enhancing decision autonomy improves the chances for successful and thus reinforceable change initiatives. If the foreign investor or high-ranking managers of the acquired company reinforce such initiatives, this also reinforces the employees' willingness to propose further initiatives as well as the managers' willingness to support these initiatives. These mechanisms facilitate the commitment and the ability of all involved to act in accord with the new cooperation model of "empowerment." Empowerment thus reinforces and supports itself and spawns further preconditions for an ever-increasing quality of cooperation as described above between the acquired company and the foreign investor.

Moreover, empowerment enhances trust. Undoubtedly, granting decision autonomy implies risks for the foreign investor, who will tend to interpret the transfer of responsibilities to managers and employees of the acquired company as an advance in regard to trust. This, in turn, makes it more likely that the foreign investor will be trusted and appreciated reciprocally (Buono/Bowditch .1989), thus engendering a dynamic reciprocal process that is also confirmed outside the context of acquisitions (Tyler/Blader. 2000). Concomitantly, the willingness to attribute a fair amount of integrity in the sense of a procedural fairness to the foreign investor will increase. This is important in the sample of acquisitions studied here because it militates against the widespread fear that the foreign investor merely seeks to brazenly maximize short-term profits.

As stated above, intermediate successes indicate that the right path is being followed and that the new (product and market oriented) strategic orientation is beginning to pay off. The concurrent subjective explanations of this success on the part of the work force increase the chances that this new goal orientation that appears to be suitable for steering the company and all involved out of the crisis becomes a commonly shared goal orientation. This is of crucial importance, since a shared goal orientation reduces the risks of decentralized self-regulation (Gebert et al.. 2004). A 
common goal orientation is a vital medium of coordination. It fosters the coordination between the company and the foreign investor as well as the coordination between the various organizational departments (especially production and sales) within the acquired company, and thus obviates frictions regarding cooperation with the foreign investor. Moreover, a shared goal orientation facilitates the development of mutual trust and in this way enhances the quality of cooperation between the acquired company and the foreign investor.

The processes described above back the thesis that an increase in decision autonomy fosters the quality of cooperation between the acquired company and the investor. This is true, however, only if there exists a clear strategy upon which investments are based, which in turn heightens material and cognitive situational control.

This can change when the degree of the granted decision autonomy is very high. According to our understanding, high degrees of decision autonomy indicate that the employees and managers are not only responsible for deciding on which path might be appropriate for meeting previously supplied objectives. Instead, they are also responsible for deciding on which objectives concerning production, quality, and marketing are to be pursued in the first place. This may overstrain the employees and managers regarding their skills and interactive competencies, since in the beginning of the post-acquisition phase they may not yet be prepared to adequately play their part in the context of the empowerment model.

There is another problem, however, that is independent of the one just mentioned: If the foreign investor decentralizes the goalsetting process itself - i.e., if the acquired company is responsible for determining product, quality, and sales goals -, a degree of decision autonomy will be reached that may be misinterpreted, especially in the first years of the post-acquisition phase. For instance, the acquired company might ask itself if this could be a manifestation of a "laissez faire" attitude, which might indicate that the foreign investor is no longer certain about his own objectives, that he might already have set his sights on other acquisitions, or - even worse - that he might plan to abandon the acquired company after having withdrawn profits that justify the initially invested capital. Such interpretations are easily comprehensible, since a modicum of mistrust will presumably always remain in the relations with the foreign investor, and since the foreign investor's politics directly affect all members of the acquired company on an existential level. On the basis of such attributions, a very high level of decision autonomy engenders a new cognitiveemotional quality that no longer defuses threats, but instead nourishes new fears.

Doubts concerning the plans of the foreign investor jeopardize the attribution of competence and integrity. Moreover, they spawn resentments and diminish trust. The result is less openness and a decreased appreciation of the investor. All this has negative ramifications for the quality of cooperation, the enthusiasm of the work force, and thus the number of promising individual initiatives, etc., so that a negative feedback loop concerning the quality of cooperation is set in motion. This leads to:

Hypothesis 1: The relationship between the degree of decision autonomy granted to the acquired company on the one hand and the quality of cooperation between the acquired company and the foreign investor on the other is not linear, but curvilinear (inversely Ushaped). This connection is more pronounced in the first years of the post-acquisition phase.

\section{Methods}

\section{Sample}

In the years 2000 and 2001, N=29 Polish companies and $\mathrm{N}=16$ companies from the Russian Federation, whose acquisition by German investors occurred five years ago (on average), participated in the study. All of these companies were medium-sized manufacturing companies from various industrial sectors: energy, chemistry, industrial engineering, construction, food. Most of them had a work force of 200-1000 employees. Of the $\mathrm{N}=95$ companies that were contacted - this number probably approximates the total number of German acquisitions in Poland and the Russian Federation (Piske, 2003) - 46\% agreed to participate. In the sample studied here, organizations and their subsidiaries are from the same industrial sector - a constellation that tends to favour the success of an acquisition (Uhlenbruck/DeCastro, 2000). There are no significant differences ( $t-$ Test) between participating and nonparticipating companies regarding industrial 
sector, number of employees, or gross revenues (Piske, 2003).

\section{Data Collection}

As is well documented theoretically and empirically - e.g., by Lawrence and Lorsch in 1967 - the different subsystems within an organization differ with respect to their leadership culture. There were some indications to this effect in the interviews conducted as a qualitative pre-study. Thus, measurements regarding the degree of decision autonomy would only yield a very restricted validity if they were collected on an aggregate level of the whole organization. Additionally, the collaboration between the foreign investor and the various subsystems of the acquired company (production, sales, etc.) could differ. There is some indication that the investor tends to view production more globally, but to organize sales more locally (Bartlett/Ghoshal, 1987), which subjects the various subsystems of the acquired company to different levels of pressure to conform to the parent company (Doz/Prahalad, 1981). Measuring the quality of cooperation between the foreign investor and the acquired company - if realized on the aggregate level of the whole organization would likewise yield no valid results. We have therefore decided to assess the quality of cooperation as well as the degree of decision autonomy on the level of the subsystems (production, sales, marketing, and finances). The relationship between decision autonomy and quality of cooperation is thus analyzed in $\mathrm{N}=187$ organizational departments.

From each organizational unit, 2-10 managers/employees were randomly selected from the organization chart for the participation in the study. Only those individuals who were already working for the organization at the time of the acquisition were eligible for random selection. Usually, the companies provided lists of these employees, from which the participants were determined by lot. A total of $\mathrm{N}=804$ employees participated in the study, with an average of 4,2 employees per organizational unit. $47,5 \%$ of the participants were women and $52,5 \%$ were men; $42,7 \%$ were managers and $57,3 \%$ were employees with no leadership functions.

All participants were led to a large room or hall (e.g., cafeteria, auditorium), where they were introduced to the research project and assured of utmost confidentiality. The participants completed the questionnaire in the presence of the second author and an interpreter. Questions were answered and it was ensured that the participants did not exchange views amongst each other regarding the questionnaire. High interrater-reliabilities (James et al., 1984) emerged for the organizational departments as well as for the respective constructs. For decision autonomy, $r_{w g}$ is 0,92 , and for quality of cooperation, $r_{w g}$ is 0,93 . The answers given by the (on average) 4,2 persons per subsystem can therefore be combined and expressed by the mean value.

\section{Measurement}

The items concerning decision autonomy and the items regarding the quality of cooperation were all measured on a 5-point Likert scale, ranging from "strongly disagree" to "strongly agree." The items for measuring decision autonomy are shown in Table 1 . In a principle component analysis of the 4 items, a first factor emerged with high loadings of all items and a $52 \%$ share of explained total variance. This justifies adding the individual values to a scale sum value. Cronbach's Alpha is $\alpha=.72$.

The items for measuring quality of cooperation are also shown in Table 1. A principle component analysis yields a first factor, upon which all items load and which explains $46,1 \%$ of the variance. Cronbach's Alpha is $\alpha=.70$.

Since the evaluations of decision autonomy and quality of cooperation are from the same person, the problem of perceptpercept inflation arises (Crampton/Wagner 1994). According to current conventions, if a factor analysis confirms that a common $\mathrm{g}$ factor underlying both variables does not exist, and that the two variables are clearly distinguishable constructs, the problem of percept-percept inflation is viewed as attenuated or as non-existent. A confirmatory factor analysis indeed corroborates the analytical distinguishability of the two constructs (correlated factors, uncorrelated residues; GFI: 0,915; AGFI: 0,882; RMSEA: $0,063)$.

\section{Analysis and Results}

Table 2 shows the correlations (the respective scale sum values) regarding the 
TABLE 1: Operationalization of the constructs (acquisition study)

\begin{tabular}{|l|l|l|}
\hline Construct & $\begin{array}{l}\text { Items } \\
\text { Measured on a five-point scale: , strongly agree “=5, ,neutral “=3, } \\
\text { strongly disagree "=1 }\end{array}$ & Cronbach's $\alpha$ \\
\hline $\begin{array}{l}\text { Eothing in our department is at the discretion of Polish/Russian } \\
\text { initiatives; the German side provides clear and detailed instructions for } \\
\text { every task. (R) } \\
\text { For the most part, the Polish/Russian side autonomously decides on how } \\
\text { to pursue the strategic goals in our department. } \\
\text { The German side determines the goals of our department (e.g., } \\
\text { production, quality, and sales goals). (R) } \\
\text { Ever since the takeover, the Germans make most of the decisions } \\
\text { concerning layoffs and promotions. (R) }\end{array}$ & $\mathbf{\alpha}=\mathbf{0 . 7 2}$ \\
\hline Eigenvalue $=\mathbf{2 , 0 7}$
\end{tabular}

\begin{tabular}{|l|l|l|}
\hline & $\begin{array}{l}\text { Most Polish/Russian colleagues in my department view the Germans as } \\
\text { very competent managers and leaders. } \\
\text { In our department, the opinion is widespread that the Germans are } \\
\text { primarily interested in exploiting cheap Polish/Russian resources and } \\
\text { workers in the short-term. (R) } \\
\text { An honest, open, and trusting relationship exists between my } \\
\text { Quality of } \\
\text { cooperation: } \\
\text { appreciation and trust } \\
\text { Problems between German and Polish/Russian employees in my } \\
\text { department are discussed openly; hardly anything is swept under the } \\
\text { rug. } \\
\text { These days, if one is dissatisfied with something in our department, it is } \\
\text { better to keep quiet about it. (R) }\end{array}$ & $\mathbf{\alpha}=\mathbf{0 . 7 0}$ \\
\hline Eigenvalue $=\mathbf{2 , 3 0}$ & \multicolumn{1}{|c|}{ explained total variance $=\mathbf{4 6 , 1 \%}$} \\
\hline
\end{tabular}

Note: $(\mathrm{R})=$ recoded

TABLE 2

Descriptive Statistics and Correlations ${ }^{\text {a }}$

\begin{tabular}{cccc}
\hline \multicolumn{1}{c}{ Variable } & mean & s. d. & 1 \\
\hline $\begin{array}{c}\mathbf{1} \text { decision } \\
\text { autonomy }\end{array}$ & $18.06^{\mathrm{b}}$ & 4.5 & - \\
$\mathbf{2}$ quality of \\
cooperation & $17.61^{\mathrm{b}}$ & 4.4 & $.28 * *$ \\
\hline${ }^{\mathrm{a}} \mathrm{N}=187^{\mathrm{b}}{ }^{\mathrm{b}}$ scale sum value, ${ }^{* *} \mathrm{p}<.01$ & &
\end{tabular}

TABLE 3

Results of Regression Analysis of Quality of Cooperation on Decision Autonomy

\begin{tabular}{lll}
\hline & $\begin{array}{l}\text { Model 1 } \\
\text { Linear Fit }\end{array}$ & $\begin{array}{l}\text { Model 2 } \\
\text { Quadratic Fit }\end{array}$ \\
\hline$\beta_{1}$ & $.28 * *$ & $1.39 * *$ \\
$\beta_{2}$ & - & $-1.12 *$ \\
$\mathrm{R}^{2}$ & .128 & .166 \\
$\mathrm{~N}$ & 177 & 177 \\
$\mathrm{~F}$ & $15.15 * * *$ & $11.07 * * *$ \\
$\triangle \mathrm{R}^{2}$ & - & .038 \\
$\triangle \mathrm{F}$ & - & $7.95 * *$ \\
\hline
\end{tabular}


organizational units between the degree of decision autonomy and quality of cooperation. It also provides the means and standard deviations.

In order to test hypothesis 1, a regression analysis of quality of cooperation is conducted for decision autonomy. We regard hypothesis 1 as empirically confirmed when the quadratic function explains significantly more variance than does the linear function. Thus, the gains in explained variance in the quadratic model as compared to the linear model are crucial.

For the results, see Table 3 .

The results of the regression analysis (Table 3) indicate that the relationship between the degree of decision autonomy and the quality of cooperation is inversely Ushaped. The quadratic term and the gains in explained variance are both significant. Figure 2 graphically illustrates this inverse U-shaped progression.

In order to examine the time dependency of the curvilinear progression posited in the hypothesis, we have - based on medians compared the companies whose acquisition has occurred within the last five years with those companies whose acquisition occurred more than five years ago. The comparison of the Tables 4 and 5, and the Figures 3 and 4, respectively, shows that the additionally explained variance of the curvilinear function is indeed significant and substantial in that part of the sample whose time of acquisition was more recent.

The inverse U-shaped relationship between decision autonomy and quality of cooperation with the foreign investor is thus especially pronounced and salient in the first years after the acquisition.

\section{Study 2 (Privatization)}

\section{Theory and Hypothesis}

In the second study, empowerment is defined by dialogic leadership. In contrast to a monologic leadership, which is marked by the leader's insistence that he or she is right at all times, the construct dialogic leadership pertains to a social situation in which problems are solved in a collective spirit. Dialogic leadership grants subordinates the space to feel free and voice their thoughts and doubts concerning the strategies implemented by the organization. Insofar as the influence potential of subordinates rises, dialogic leadership also comprises a variant of empowerment, namely the enhancement of the subject-status of each individual.

In this study, the successful management of intra-organizational change is measured via the innovativeness of the respective organization. Here, the construct innovativeness pertains to new products and services, but also to intra-organizational processes (cf. Table 6). Privatization was accomplished by the state's offering lowinterest loans to the work force, so that managers and employees could buy stocks of their company (employee buy-out). In contrast to the organizations of the acquisition study, there were no national or foreign investors who provided capital and thus attempted to raise material and cognitive situational control over the economic crisis. This means that the situation was still critical after the privatization and that material and cognitive situational control remained low.

From a theoretical perspective, a more negative development as compared to the acquisition study thus appears to be inevitable. In the absence of the crucial catalyst - the increase of material and cognitive situational control over the economic crisis through investments, for example - all offers of empowerment (in the form of dialogic leadership) will tend to fail. Due to the objective lack of material and cognitive situational control, dialogic leadership is not able to generate functional action options. Thus, the chances for the generation of partially successful and reinforceable change initiatives are slim. Accordingly, the positive development described in conjunction with the acquisition study does not ensue here. Instead, feelings of helplessness in the face of a threatening constellation arise, in turn engendering resignation and disorientation (Lazarus, 1991).

A second decisive and unfavourable context condition in the case of the privatization study is the absence of a clear and commonly shared goal orientation, which means that the companies also lacked cognitive situational control. Such a goal orientation may be indispensable in coping with the economic crisis. There are two reasons for why the privatized natural gas companies lack this shared goal orientation. Firstly, there is no investor, who usually provides clear strategic objectives along with his investments. Secondly, due to the low situational control, there are few, if any, 
Figure 2:

RESUlts of REgRession ANALYSIS OF QUALITY OF COOPERATION ON DECISION AUTONOMY*

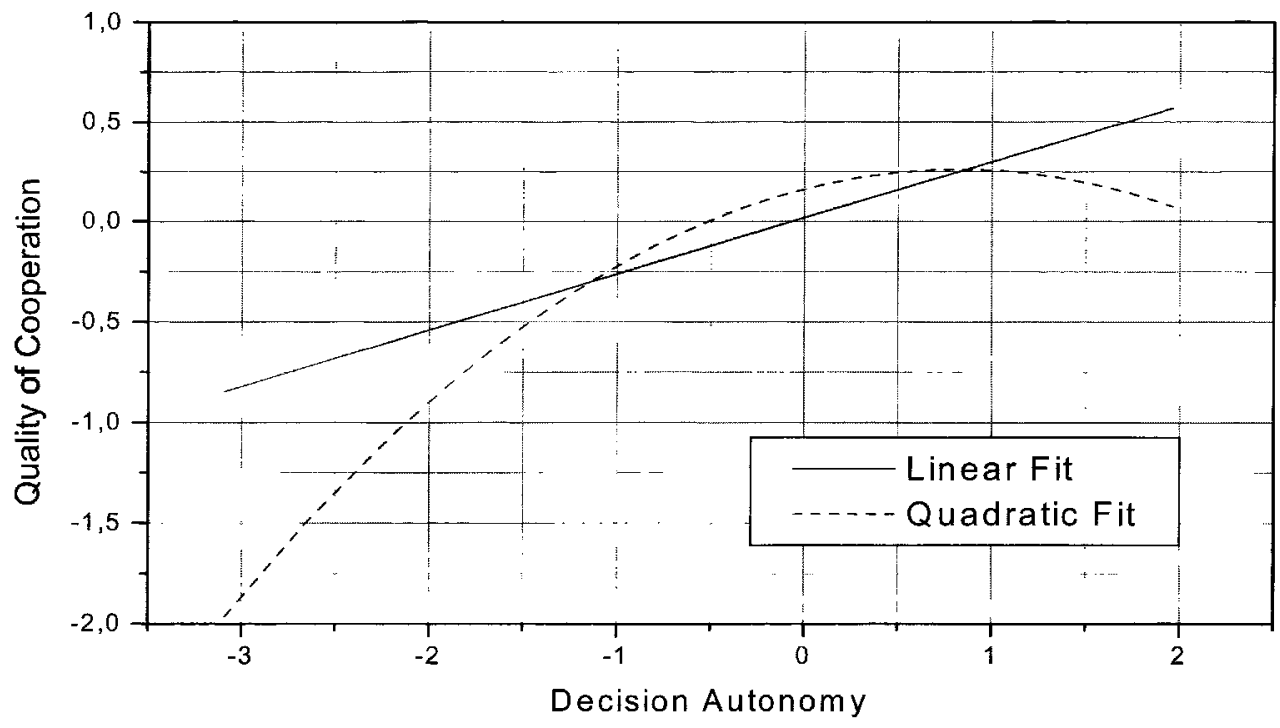

*variables were z-standardized

TABLE 4

Results of Regression Analysis of Quality of Cooperation in Older Acquisitions on Dialogic Leadership

\begin{tabular}{lcc}
\hline & $\begin{array}{c}\text { Model 1 } \\
\text { Linear Fit }\end{array}$ & $\begin{array}{c}\text { Model 2 } \\
\text { Quadratic Fit }\end{array}$ \\
\hline$\beta_{l}$ & $0,27^{* *}$ & 0,68 \\
$\beta_{2}$ & - & $-0,41$ \\
$\mathrm{R}^{2}$ & 0,073 & 0,078 \\
$\mathrm{~N}$ & 90 & 90 \\
$\mathrm{~F}$ & $7,01^{* *}$ & $3,73^{*}$ \\
$\triangle \mathrm{R}^{2}$ & & 0,005 \\
$\triangle \mathrm{F}$ & 0,49 \\
\hline \multicolumn{2}{c}{${ }^{*} \mathrm{p}<.05,{ }^{* *} \mathrm{p}<.01,{ }^{* * *} \mathrm{p}<.001$} &
\end{tabular}

TABLE 5

Results of Regression Analysis of Quality of Cooperation in Recent Acquisitions on Dialogic Leadership

\begin{tabular}{lcc}
\hline & $\begin{array}{c}\text { Model 1 } \\
\text { Linear Fit }\end{array}$ & $\begin{array}{c}\text { Model 2 } \\
\text { Quadratic Fit }\end{array}$ \\
\hline$\beta_{1}$ & $0,32^{* *}$ & $2,16^{* *}$ \\
$\beta_{2}$ & - & $-1,86^{* *}$ \\
$\mathrm{R}^{2}$ & 0,101 & 0,1834 \\
$\mathrm{~N}$ & 88 & 88 \\
$\mathrm{~F}$ & $9,78^{* *}$ & $9,65^{* * *}$ \\
$\triangle \mathrm{R}^{2}$ & & 0,083 \\
$\triangle \mathrm{F}$ & & $8,66^{* * *}$ \\
\hline \multicolumn{2}{c}{$\mathrm{p}<.05,{ }^{* *} \mathrm{p}<.01,{ }^{* * *} \mathrm{p}<.001$} &
\end{tabular}


FIGURE 3: Results of Regression Analysis of Quality of Cooperation in Older Acquisitions on Decision Autonomy*

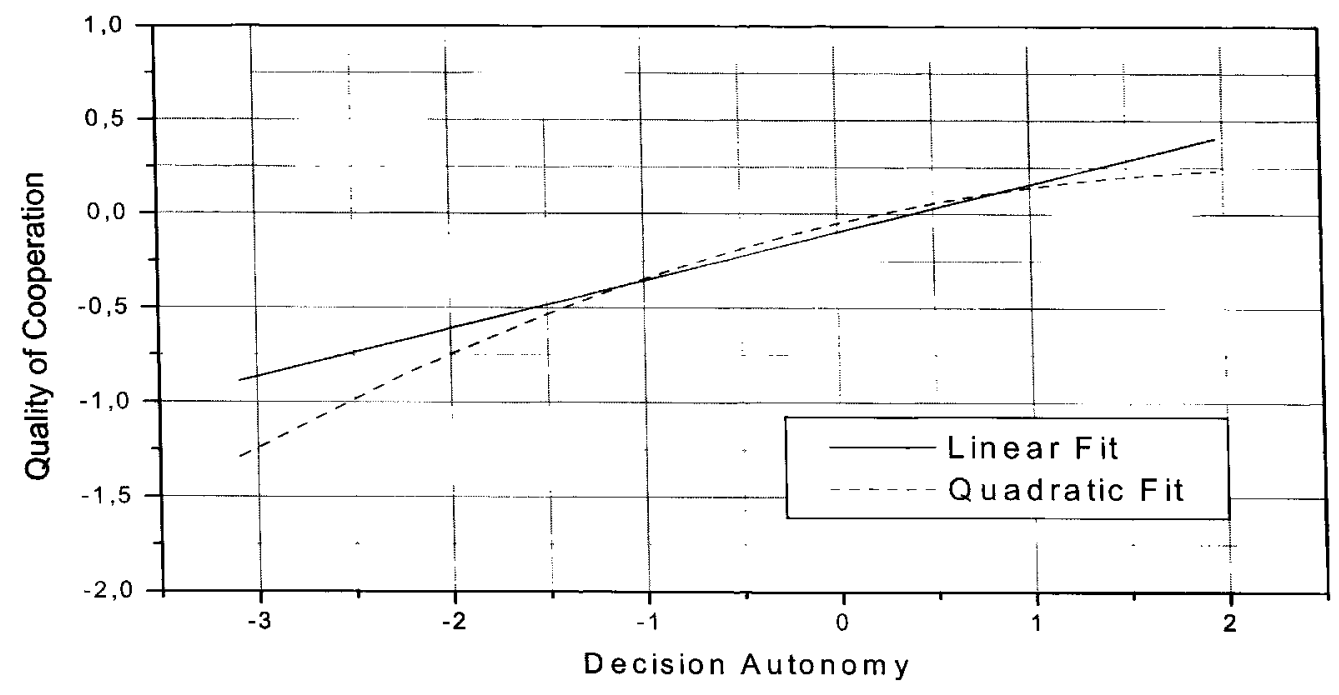

*variables were z-standardized

FIGURE 4:

Results of regression analysis of Quality of Cooperation in Recent Acquisitions on Decision Autonomy*

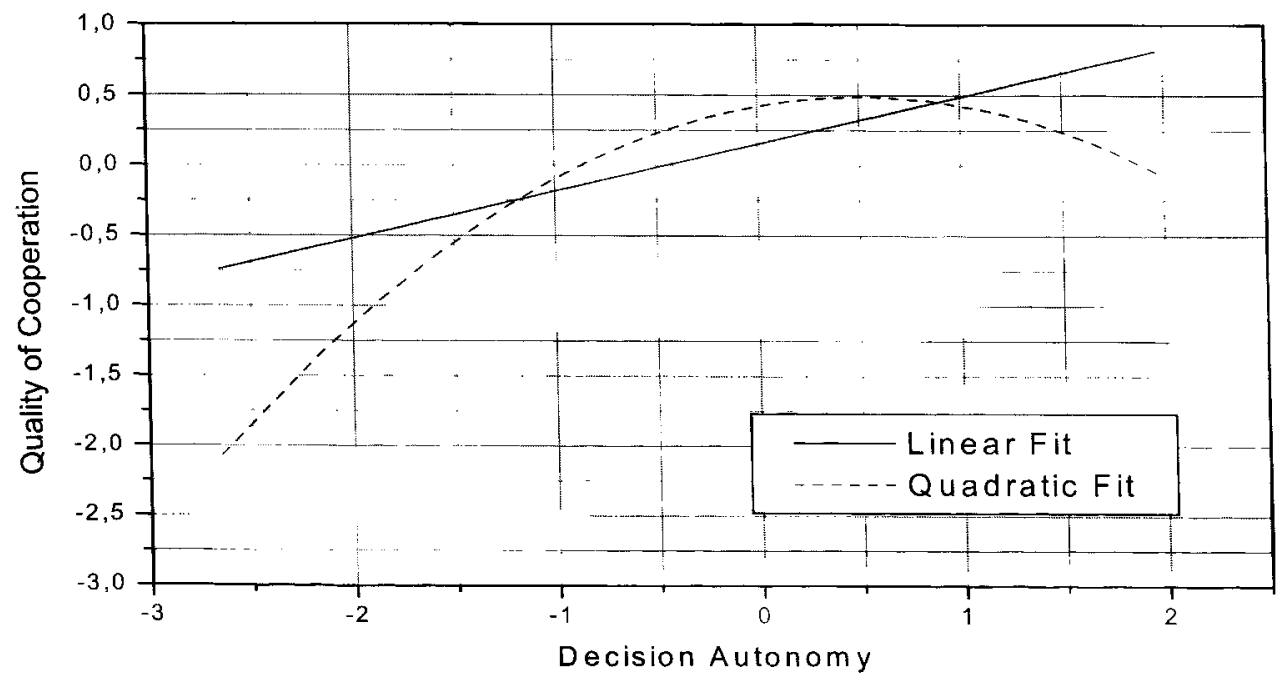

*variables were z-standardized

intermediate successes that - as was the case in the acquisition study - foster the development of a goal orientation that spawns hopes for ending the crisis and thus becomes a commonly shared goal orientation.

Consequently, this means that - in a context of low material situational control and as the result of the lack of a clear and commonly shared goal orientation - an empowerment process characterized by dialogic leadership increases the level of conflicts and thus militates against the prerequisites for the development of clear and shared goals. In the absence of a clear and 
Table 6: Operationalization of the constructs (privatization study)

\begin{tabular}{|c|c|c|}
\hline Construct & $\begin{array}{l}\text { Items } \\
\text { Measured on a five-point scale: ,, strongly agree " }=5, \text {,neutral" }=3 \text {, } \\
\text { "strongly disagree" }=1\end{array}$ & Cronbach's $\alpha$ \\
\hline $\begin{array}{l}\text { Empowerment: } \\
\text { dialogic leadership } \\
\text { (critical upward } \\
\text { communication) }\end{array}$ & $\begin{array}{l}\text { Employees openly say what they think. } \\
\text { Managers accusingly instruct employees on a daily basis. (R) } \\
\text { One may have, but one may definitely not voice general doubts } \\
\text { concerning the correct approach in this department. (R) }\end{array}$ & $\alpha=0.73$ \\
\hline \multicolumn{3}{|c|}{ Eigenvalue $=1,96 \quad$ explained total variance $=65,0 \%$} \\
\hline Construct & $\begin{array}{l}\text { Question } \\
\text { "Compared to your best competitor, is the situation in your } \\
\text { department worse, equal to, or better regarding the following } \\
\text { processes? } \\
\text { (Please consider the comparable functional department of your } \\
\text { competitor!)" }\end{array}$ & Cronbach's $\alpha$ \\
\hline $\begin{array}{l}\text { Innovativeness in } \\
\text { comparison to } \\
\text { competitors }\end{array}$ & $\begin{array}{l}\text { New operational procedures } \\
\text { New forms of organization } \\
\text { Number of improvisations during the implementation } \\
\text { Spectrum of new products } \\
\text { Activity in new markets }\end{array}$ & $\alpha=\mathbf{0 . 6 7}$ \\
\hline Eigenvalue $=2,72$ & explained total variance $=\mathbf{4 5 , 0} \%$ & \\
\hline
\end{tabular}

Note: $(\mathrm{R})=$ recoded

common goal orientation, the already scarce resources are not focused on a few (promising) activities. Thus, increases in dialogic leadership do not result in more, but in fewer impulses for innovation that are implemented effectively.

Under favourable conditions, this process of a self-sustaining downward spiral could end if the shareholders view their capital as seriously threatened and realize that a modicum of a clear and shared goal orientation is indispensable for managing the crisis. Nevertheless, such a realization should not be taken for granted. In the context of the form of transformational change studied here (privatization through employee buy-out), however, the chances for such an insight are relatively high: Privatizations of this kind constitute a form of a positive sum game. If the company is successful, the price of the shares rises for all involved (result interdependence, as described by Wageman [2001]). From the perspective of attribution theory, it is likely that the work force of the respective companies will see a connection between their own initiatives and the success of the company because these are rather small medium-sized companies. Thus, the combination of a monetary positive sum game and the small size of the companies entails a motivational potential that may be activated in order to generate a clear and commonly shared goal orientation.

If the attempt succeeds to develop a clear and shared goal orientation on this basis, increases in dialogic leadership will enhance the discernment of the few action options available (low situational control) and the transformation of these action options into a sensible collective plan of action. This, in turn, may once again engender a rising rate of innovations. (An example that we became aware of ex post: Natural gas companies attempted to utilize the already certified work processes for drilling gas fields for the installation of drinking water wells [Baga, 2004]. This enabled the development of a new product for which an outlet market existed.) This leads to:

Hypothesis 2: In the privatized companies of the Romanian natural gas industry, the relationship between the degree of dialogic leadership on the one hand and innovativeness on the other is not linear, but curvilinear (U-shaped). 


\section{Methods}

\section{Sample}

$\mathrm{N}=5$ privatized medium-sized companies (with 350 employees on average) from the Romanian natural gas industry whose privatization occurred in the late 1990 s in the way described above participated in this study, which was conducted in the year 2003. The third author is Romanian, and she was able to contact $\mathrm{N}=10$ companies out of the (estimated) population of approximately $\mathrm{N}=30$ privatized natural gas companies. $\mathrm{N}=5$ of these companies agreed to participate. Systematic differences between the participating companies and those who declined are not known.

\section{Measurement}

For the same reasons already described in the section on the acquisition study, in this study we have also measured the independent variable empowerment (dialogic leadership) as well as the dependent variable innovativeness on the level of organizational departments. We were thus able to statistically examine the relationship of interest in $\mathrm{N}=24$ subsystems.

For measuring the construct empowerment (dialogic leadership), items on a 5-point Likert scale were presented. These items can be found in Table 6 in the appendix. A principle component analysis yielded a factor with an Eigenvalue of 1,96, with high loadings of all items. This factor explains $65 \%$ of the variance. Thus, the calculation of a sum value for each subsystem is justified. Cronbach's Alpha is $\alpha=.73$.

The items for measuring the construct innovativeness are also contained in Table 6 . A principle component analysis yields a factor with an Eigenvalue of 2,72, with high loadings of all items. This factor explains $45 \%$ of the variance. Cronbach's Alpha is $\alpha=.67$. A sum value is also calculated regarding innovativeness.

In each subsystem, a manager selected at random assessed the degree of empowerment and another manager evaluated the degree of innovativeness of the respective subsystem. Both ratings were independent of one another. Thus, our data were collected from $\mathrm{N}=48$ managers (predominantly middle-level managers). The problem of percept-percept inflation (Crampton/Wagner, 1994) does not arise in the privatization study.

\section{Analysis and results}

Table 7 shows the descriptive statistics concerning the two variables as well as the correlation.

The statistical analysis was analogous to Study 1. The hypothesis 2 is regarded as confirmed when the quadratic term explains significantly more variance than does the linear term. The result of this analysis is shown in Table 8.

In assuming a linear relationship between empowerment and innovativeness, merely $3 \%$ of the innovation variance can be explained (non-significant result). Contrariwise, in assuming a U-shaped relationship between empowerment and innovativeness, $20 \%$ of the innovation variance can be explained (significant result). The $17 \%$ gain in explained variance is likewise significant. We therefore regard Hypothesis 2 as confirmed. Figure 5 graphically illustrates the examined connection.

\section{General Discussion}

\section{Limitations}

In a long-term research project, it is not always possible to determine precisely which assumptions were posited ex ante and which ones were developed ex post. Many of the arguments reported above were indeed formulated ex ante and guided us in our research. As mentioned above, however, some specific explanations of the respective findings of the two partial studies were developed after having reflected on the different results of the studies. Thus, our study is of an explorative nature; the central hypotheses require further study. The empirical findings, which we believe to be of high relevance theoretically and practically, as well as our attempts at providing a thorough and comprehensive explanation for these findings may serve to inspire such further research.

In order to test the appropriateness of the explanations provided here, longitudinal studies would be most helpful. This can be deduced from the findings presented in Tables 4 and 5, respectively. Only through longitudinal research could the dynamics of positive and negative feedback processes be studied in detail. We have only analyzed cross-sectional data. This is another limitation of our study.

Lastly, the results of the privatization study are to be viewed with caution, because 
TABLE 7

Descriptive Statistics and Correlations ${ }^{\text {a }}$

\begin{tabular}{lccl}
\hline \multicolumn{1}{c}{ Variable } & mean & s. d. & 1 \\
\hline $\begin{array}{l}\text { 1 Dialogical } \\
\text { Leadership }\end{array}$ & 9,67 & 4,03 & - \\
2 Innovativeness & 11,00 & 2,03 &,- 17 \\
\hline
\end{tabular}

${ }^{\mathrm{a}} \mathrm{N}=25,{ }^{\mathrm{b}}$ scale sum value

TABle 8

Results of Regression Analysis of Innovativeness on Dialogic Leadership

\begin{tabular}{lll}
\hline & $\begin{array}{c}\text { Model 1 } \\
\text { Linear Fit }\end{array}$ & \multicolumn{1}{c}{$\begin{array}{c}\text { Model 2 } \\
\text { Quadratic Fit }\end{array}$} \\
\hline$\beta_{I}$ & -.17 & .07 \\
$\beta_{2}$ & - & $.51 *$ \\
$\mathrm{R}^{2}$ & .030 & .200 \\
$\mathrm{~N}$ & 24 & 24 \\
$\mathrm{~F}$ & .432 & $3.98 * *$ \\
$\triangle \mathrm{R}^{2}$ & - & .170 \\
$\triangle \mathrm{F} \quad$ & $3.54 * * *$ \\
\hline \multicolumn{2}{r}{$* \mathrm{p}<.05,{ }^{* *} \mathrm{p}<.01$} &
\end{tabular}

FIGURE 5: Results of Regression Analysis of Innovativeness on Dialogic Leadership*

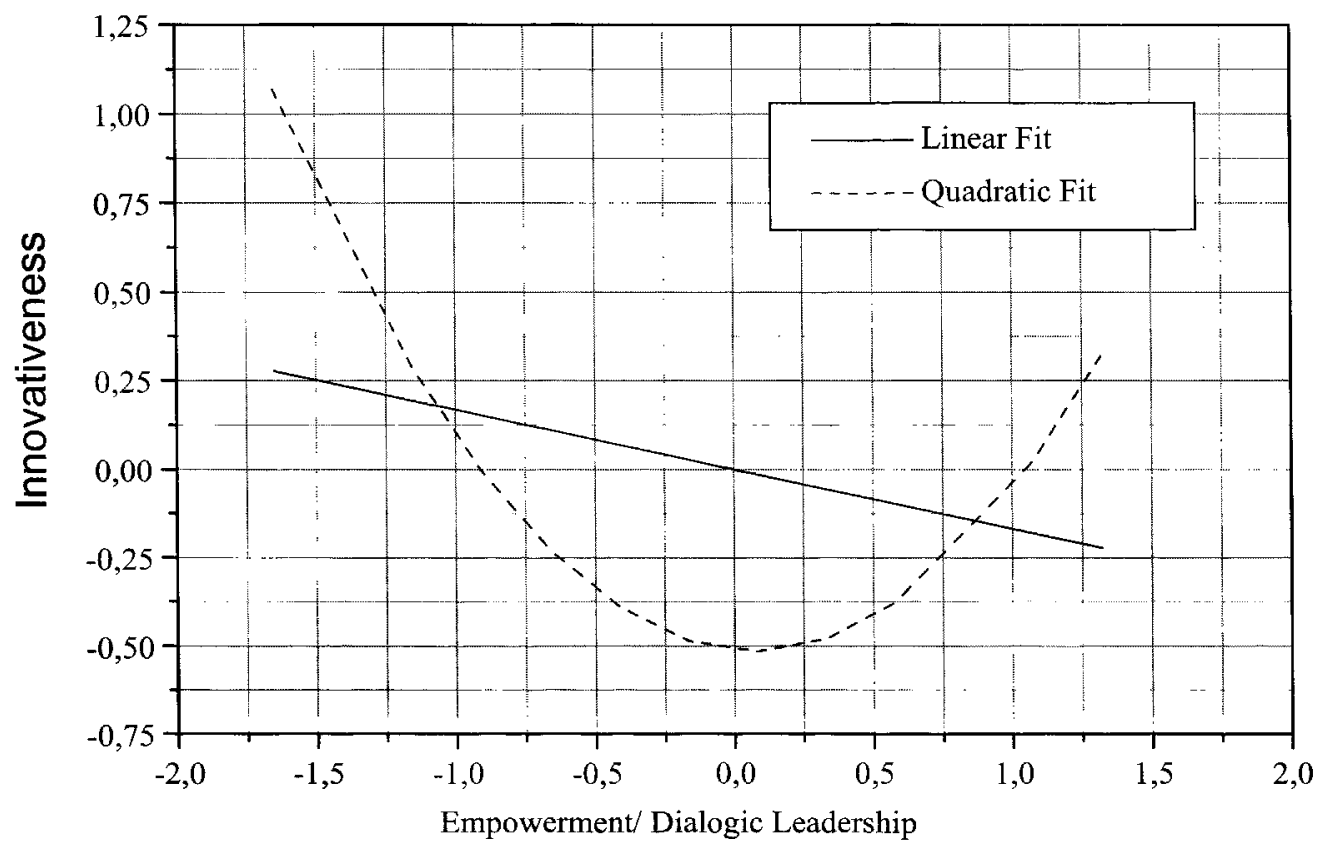

*variables were z-standardized 
the sample is comparably small. In this study, only one person assessed the independent variable and another assessed the dependent variable.

\section{Summary}

We see the central results of our analysis in the following two findings: Firstly, the effects of empowerment depend upon the respective context. In our study, the decisive context variable was the type of transformational change. Takeovers by foreign investors are connected with a material and cognitive enhancement of situational control; in this context, empowerment is therefore primarily an opportunity. In contrast, privatizations in the form of a management buy-out are not systematically connected with the theoretically crucial two-fold enhancement of situational control. In this context, empowerment thus constitutes more of a risk. Secondly, the relationship between empowerment and change management is not (primarily) linear, but curvilinear. Therefore, in the context of acquisitions by foreign investors empowerment also entails risks. Likewise, in the context of privatizations in the form of management buy-out empowerment also entails opportunities. Both studies illustrate that the prevalent linear assumptions ("the more, the better" or "the less, the better") are inappropriate. The curvilinear functions reveal that not only is the context in which empowerment occurs important with regard to success, but also the respective level of empowerment.

\section{Managerial Implications}

\section{Material Situational Control}

Viewing both studies simultaneously gives the impression that - given a high discrepancy between the economical crisis on the one hand and the objective (!) coping options on the other - empowerment in the sense of granting decision autonomy and/or facilitating dialogic leadership (critical upward communication) may cause more harm than good. Carried to the extreme, if objectively no action options exist, decentralizing decision competencies and a dialogic leadership style may only bring about internal adaptation processes (i.e., a lowering of standards) and disorientation.
Success depends on the combination of conveying objective action options on the one hand and facilitating empowerment on the other. Stated bluntly, empowerment without situational control is useless. Situational control without empowerment will only suboptimally make use of the crisis management potential inherent in situational control. Thus, one variable is not (sufficiently) effective without the other.

Herein lies the described importance of the investments in the acquisition sample. In these companies, empowerment is initially connected with the quality of cooperation for this reason. In the context of transformational change, empowerment is only expedient as a leadership tool if the management can actively create action alternatives (e.g., through investments, political negotiations, etc.).

\section{Cognitive Situational Control}

According to our interpretation, coping with an economic crisis via transformational change requires a clear and commonly shared goal orientation, without which a concerted collective focus on a few initiatives is not possible (Gebert et al., 2002). The adequate and consensual evaluation of action options requires a clear and shared goal orientation, which is necessary for prioritizing feasible and promising projects. It must therefore be specified what empowerment should consist of (Wageman, 2001) and, at the same time, what its restrictions are (Gebert/Boerner, 1999). Strategic plans of German investors do not contradict the idea of empowerment. On the contrary, they are the preconditions for empowerment.

Thus, we view the parallel enhancement of material and cognitive situational control combined with empowerment as the constellation with the greatest potential for overcoming the crisis.

\section{Positive Sum Game and Organization Development}

Establishing a positive sum game (result interdependence) should be helpful particularly in smaller companies. In our view, the facilitation of a positive sum game is the great promise of an employee buy-out over the course of a few years. Based on this positive sum game, the chances increase for the development of a clear and commonly shared goal orientation, which in turn makes it more likely that task conflicts (Jehn, 1995), which 
are inevitable and necessary for the generation of innovativeness, will be solved. This process can be reinforced through organization development (Gebert, 2002) and transformational leadership as described by Shamir et al., (1993). If the communication of an attractive vision of the future is successful (Baum et al. 1998), this also fosters a shared social identity (Kane et al., 2002). Thus, it provides the preconditions that make it possible for decision autonomy and dialogic leadership to generate functional effects (as is shown empirically in the once again rising $U$ curve in the privatized companies).

Moreover, according to our interpretation of the data, a management development program that includes organizational behavior modification (Luthans \& Kreitner, 1985) is necessary that enables managers and employees technically and interactively to live up to the requirements of the cooperation model that is implied by empowerment.

If all of these prerequisites (including material and cognitive situational control) are met, we think it is very likely that empowerment will then show not a curvilinear, but a positive linear relationship with change management.

\section{Balancing Opposing Processes}

As indicated, we furthermore interpret the results to indicate that the empowerment measures increasing the personnel's leeway (opening processes) must be applied in conjunction with restricting measures (closing processes in the sense of goal-setting and strategy transmission) (Gebert/Boerner, 1999), in order to establish a balance between centrifugal and centripetal forces within the organization (Sheremata, 2000). It is precisely this balance which was markedly absent in the privatized companies. If, therefore, not only freedoms are called for in managing the crisis, but also a freedom-restraining leadership (goal communication, etc.), it is understandable that the delegation of this goal-setting process in the acquisition study enhances the attribution of a lack of leadership and is thus perceived as threatening. According to our findings, this danger is particularly salient in the first years of the post-acquisition phase.

\section{References}

Baga, T. (2004). Transformationsprozesse in rumänischen Unternehmen und Unternehmenserfolg. Berlin: Technische Universität, Fachgebiet Organisation, Personalwesen und Führungslehre.

Bartlett, C. A. \& Ghoshal, S. (1987). Managing across borders: New organizational responses. Sloan Management Review, 29 (1), 43-53.

Baum, J. R., Locke, E. A., \& Kirkpatrick, S. A. (1998). A longitudinal study of the relation of vision and vision communication to venture growth in entrepreneurial firms. Journal of Applied Psychology, 83 (1), 43-54.

Buono, A. F. \& Bowditch, J. L. (1989). The human side of mergers and acquisitions: Managing collisions between people, cultures and organizations. San Francisco: Jossey-Bass.

Cartwright, S. \& Cooper, C. L. (1996). Managing mergers, acquisitions and strategic alliances: Integrating people and cultures. Oxford: ButterworthHeinemann.

Crampton, S. \& Wagner, J. (1994). Perceptpercept inflation in microorganizational research: An investigation of prevalence and effect. Journal of Applied Psychology, 79 (1), 67-76.

Doz, Y. L. \& Prahalad, C. J. (1981). Headquarters influence and strategic control in multinational enterprise. Sloan Management Review, Fall, 15-29.

Gebert, D. (2002). Organization development. In: A. Sorge (Ed.), Organization. (pp. 432-455) London: Thomson Learning.

Boerner, S. \& Gebert, D. (1997). Unternehmen zwischen Resignation und Hoffnung Ergebnisse einer Fallstudie in einem Moskauer Betrieb. Journal for East European Management Studies (JEEMS), 2 (3), 305-336.

Fiol, C. M., Harris, D., \& House, R. (1999). Charismatic leadership: Strategies for effecting social change. Leadership Quarterly, 10 (3), 449-482.

Gebert, D. \& Boerner, S. (1999). The open and the closed corporation as conflicting forms of organization. Journal of Applied Behavioral Science, 35 (3), 341-359. 
Gebert, D., Boerner, S., \& Lanwehr, R. (2002). Promoting organizational innovativeness: Balancing chances and risks of situation control. Paper presented at The Academy of Management Meeting, August 9-14, Denver Colorado.

Gebert, D., Boemer, S., \& Lanwehr, R. (2004). The more situation control, the more innovation? Putting the linearity thesis to the test. International Journal of Entrepreneurship and Innovation Management, 4 (1), 98-114.

Gersick, C. J. G. (1991). Revolutionary change theories: A multilevel exploration of the punctuated equilibrium paradigm. Academy of Management Review, 16 (1), 10-36.

Greenwood, R. \& Hinings, C. R. (1996): Understanding radical organizational change: Bringing together the old and new institutionalism. Academy of Management Review, 21 (4), 1022-1054.

Hambrick, D. C. \& Canella, A. A. (1993). Relative standing: A framework for understanding departures of acquired executives. Academy of Management Journal, 36 (4), 733-762.

Hardy, C. \& Leiba-O'Sullivan, S. (1998). The power behind empowerment: Implications for research and practice. Human Relations, 51 (4), 451-483.

Herrenkohl, R. C., Judson, G. T., \& Heffner, J. A. (1999). Defining and measuring employee empowerment. Journal of Applied Behavioral Science, 35 (3), 373389.

James, L. R., Demaree, R. G., \& Wolf, G. (1984). Estimating the within-group interrater reliability with and without response bias. Journal of Applied Psychology, 69 (1), 85-98.

Jehn, K. A. (1995). A multimethod examination of the benefit and detriments of intragroup conflict. Administrative Science Quarterly, 40 (2), 256-282.

Kane, A., Argote, L., \& Levine, J. M. (2002). Social identity and knowledge transfer between groups. Paper presented at the The Academy of Management Meeting, Denver 2002.

Kelly, M. J., Schaan, J.-L., \& Joncas, H. (2002). Managing alliance relationships: Key challenges in the early stages of collaboration. $R \& D$ Management, 32 (1), $11-22$
Larsson, R. \& Lubatkin, M. (2001). Achieving acculturation in mergers and acquisitions: An international case survey. Human Relations, 54 (12), 1573-1605.

Lawrence, P. J. \& Lorsch, J. (1967). Organization and environment. Boston: Harvard Graduate School of Business Administration.

Lazarus, R. S. (1991). Emotion and adaptation. New York: Oxford University Press.

Leach, D. J., Wall, T. D., Rogelberg, S. G., \& Jackson, P. R. (2005). Team autonomy, performance, and member job strain: Uncovering the teamwork KSA link. Applied Psychology: An international review, 54 (1), 1-24.

Luthans, F. \& Kreitner. R. (1985). Organizational behavior modification and beyond: An operand and social learning approach (2nd ed.). Glenview, IL: Scott, Foresman.

Marks, M. L. \& Mirvis, P. H. (2001). Making mergers and acquisitions work: Strategic and psychological preparation. Academy of Management Executive, 15 (2), 80-94.

Pearce, C. L. \& Sims Jr., H. P. (2002). Vertical versus Shared Leadership as Predictors of the Effectiveness of Change Management Teams: An Examination of Aversive, Directive, Transactional, Transformational, and Empowering Leader Behaviors. Group Dynamics: Theory, Research, and Practice, 6 (2), 172-197.

Piske, R. (2003). Integration management as a moderator of the impact of cultural diversity on conflict and cooperation after German Acquisitions in Eastern Europe. Paper presented at the 11th European Congress of Work and Organizational Psychology, May 14-17, Lisbon, Portugal.

Romanelli, E. \& Tushman, M. L. (1994). Organizational transformation as punctuated equilibrium: An empirical test. Academy of Management Journal, 37 (6), 1141-1166.

Shamir, B., House, R. J., \& Arthur, M. B. (1993). The motivational effects of charismatic leadership: A self-concept based theory. Organization Science, 4 (4), 577-594. 
Sheremata, W. A. (2000). Centrifugal and centripetal forces in radical new product development under time pressure. Academy of Management Review, 25 (2), 389-408.

Staniszkis, J. (1991). Dilemmata der Demokratie in Osteuropa. In: R. Deppe, H. Dubiel, \& U. Rödel (Hrsg.) Demokratischer Umbruch in Osteuropa. (S. 326-347). Frankfurt am Main: Suhrkamp.

Tushman, M. L. \& Romanelli, E. (1985). Organization evolution: A metamorphosis model of convergence and reorientation. In: L. L. Cummings \& B. M. Staw (Eds.), Research in organizational behavior (Volume 7). (pp. 171-222). Greenwich.
Tyler, T. R. \& Blader, S. L. (2000). Cooperation in groups. Procedural justice, social identity, and behavioral engagement. Ann Arbor: BraunBrumfield.

Uhlenbruck, K. \& De Castro, J. (2000). Foreign acquisitions in central and eastern Europe: Outcomes of privatization in transitional economies. Academy of Management Journal, 43 (3), 381-402.

Wageman, R. (2001). How leaders foster selfmanaging team effectiveness: Design choices versus hands-on coaching. Organization Science, 12 (5), 559-577.

\section{Journal of Leadership w organizational Studies}

\section{Subscription Information 2005-2006}

Published by Baker College since 1993, The Journal of Leadership and Organizational

Studies is a solid investment in today's education.

$$
\begin{gathered}
\text { Subscription Rates: } \\
\text { One Year - } \$ 89.95 \\
\text { Two Year - } \$ 175.00 \\
\text { Three Year - } \$ 260.00 \\
\text { Student Rate - } \$ 65.00
\end{gathered}
$$

For questions and ordering information, please contact:

Julia A. Teahen, Managing Editor

Journal of Leadership and Organizational Studies

Baker College

1116 West Bristol Road

Flint, MI 48507

E-Mail: Julia@baker.edu

Website: https://www.baker.edu/departments/leadership/jls-main.cfm 